\title{
EL MUSÉE D'ART MODERNE ANDRÉ MALRAUX: EL MUSEO-TIPO DE LA MODERNIDAD FRANCESA
}

THE MUSÉE D'ART MODERNE ANDRÉ MALRAUX: THE MUSEUM-TYPE OF FRENCH MODERNITY

Inmaculada Real López

Universidad de Zaragoza

Resumen

Palabras clave

Abstract

Keywords
Este artículo realiza un estudio del panorama museístico en Francia tras la Segunda Guerra Mundial, en concreto de Le Havre. El objetivo es demostrar los avances que se producen en esta ciudad desde el ámbito de la museología, en medio del proceso de reconstrucción urbanística debido a la devastación producida por el conflicto bélico. En los años cincuenta se recupera el museo provincial, el cual surge con una perspectiva americana y con claves de modernidad, lo que le convierte en un museo-tipo y en el referente de la museología francesa. Además, anticipa una serie de valores sociales y democráticos que comulgan con las Maisons de la Culture de André Malraux, razón por la cual fue sede de esta institución y se consideró el modelo a seguir. A su vez, el museo mantiene un continuo diálogo con el entorno urbanístico y el arte contemporáneo instalado en el espacio público.

Museología, socialdemocracia, arte urbano, Maisons de la Culture, arquitectura, modernidad.

This paper carries out a study of the museum scene in France after the Second World War, in particular Le Havre. The aim is to demonstrate the advances that take place in this city from the field of museology, in the middle of the process of urban reconstruction due to the devastation produced by the war. In the fifties the provincial museum was recovered, which emerged with an American perspective and with keys to modernity, making it a model museum and the benchmark for French museology. In addition, it anticipates a series of social and democratic values that commune with André Malraux’s Maisons de la Culture, which is why it was the headquarters of this institution and was considered a model to follow. At the same time, the museum maintains a continuous dialogue with the urban environment and contemporary art installed in the public space. Museology, Social Democracy, Urban Art, Maisons de la Culture, Architecture, Modernity. 


\section{Introducción}

Con la creación del Ministère d'Affaires Culturelles en 1959, se puso en marcha un modelo de institución denominado Maison de la Culture que fue ideado por André Malraux, y que estaba basado en la dinamización socialdemocrática y en la liberación cultural mediante un espacio polivalente que permitiera el acceso de la población al conocimiento y a la educación. A su vez, se trataba de un modelo de gestión descentralizado que impulsaba la creación de varios centros culturales por diferentes ciudades francesas durante la década de los sesenta, para dar respuesta a una nueva demanda social de carácter multidisciplinar. De todas las Maisons fundadas, la primera que apareció fue la de Le Havre, que se inauguró en 1961 y marcó el punto de partida de la modernidad en la vida cultural francesa. De hecho, el propio André Malraux llegó a indicar «no hay una casa como esta en el mundo, incluso ni en Brasil, ni en Rusia ni en Estados Unidos» (Royer y Barot, 2016: 9). De esta forma dejaba claro el carácter excepcional que tenía esta primera Maison, la cual presentaba la peculiaridad de compartir sede con el museo municipal de la ciudad que acababa de renacer tras haber sido devastado durante la Segunda Guerra Mundial. Al mismo tiempo que había una necesidad por restaurar los edificios destruidos, se quería recuperar moralmente a una población que había sido testigo directo de la destrucción de los espacios culturales más representativos: el Museo de Bellas Artes y el Teatro Municipal.

El entonces denominado Musée du Havre se convirtió en el proyecto piloto ${ }^{1}$ de socialización y democratización del arte más relevante de la época, el cual se vio notablemente favorecido por la hibridación institucional promovida por Malraux. Sería en 1972, en la Declaración de la Mesa Redonda de Santiago de Chile

1 Así se presenta en algunas guías de museos como en la de Pierre Cabanne (1990: 280) sobre el desarrollo y el papel de los museos en el Mundo Contemporáneo, en donde quedaría definido que «el museo es parte integral de la sociedad» (De Varine, 2014: 32), y que debe responder a las demandas de esta. Por tanto, los criterios de estas dos instituciones francesas se adelantaron al reconocimiento social de acceso a la cultura, de tal manera que ambas aunaron tales criterios, pues se abrían a la población obrera para que esta tuviera acceso al patrimonio universal, a los bienes culturales y al conocimiento. Esta fusión fue posible porque en 1952 había surgido en la ciudad portuaria el primer gran museo construido tras la Segunda Guerra Mundial, anterior incluso al Musée d'Art Moderne de la Ville de París, que se inauguró en 1955. Asimismo, por su planteamiento y diseño arquitectónico se aproximaba a lo que Malraux concebía como el nuevo modelo institucional que debía emerger en Francia. Este paralelismo dio lugar a la creación, desde 1961 hasta 1967, del denominado MuséeMaison de la Culture, el cual se convirtió en el proyecto de referencia del Ministère d'Affaires Culturelles, que pretendía llevar a cabo una descentralización de la cultura para que esta llegara a todas las provincias y no estuviera exclusivamente reservada a los habitantes de la capital, y también para revitalizar los centros históricos. De hecho, para cumplir con este objetivo se había previsto construir hasta veintiuna Maisons de la Culture por todo el territorio francés, aunque finalmente no todas se llegaron a realizar ${ }^{2}$.

En aquellos años el ministro Malraux vio cómo se materializaba la idea de crear «un lugar abierto a todas las artes, abierto a todos los públicos, un lugar de alegría, de sorpresa, de descubrimiento y de admiración ${ }^{3}$, y también de emoción, como llegó a señalar, porque

2 Véase por ejemplo el caso fallido de la Maison de la Culture de Rouen en Inmaculada Real López (2019)

3 «Impression, Le Havre» 


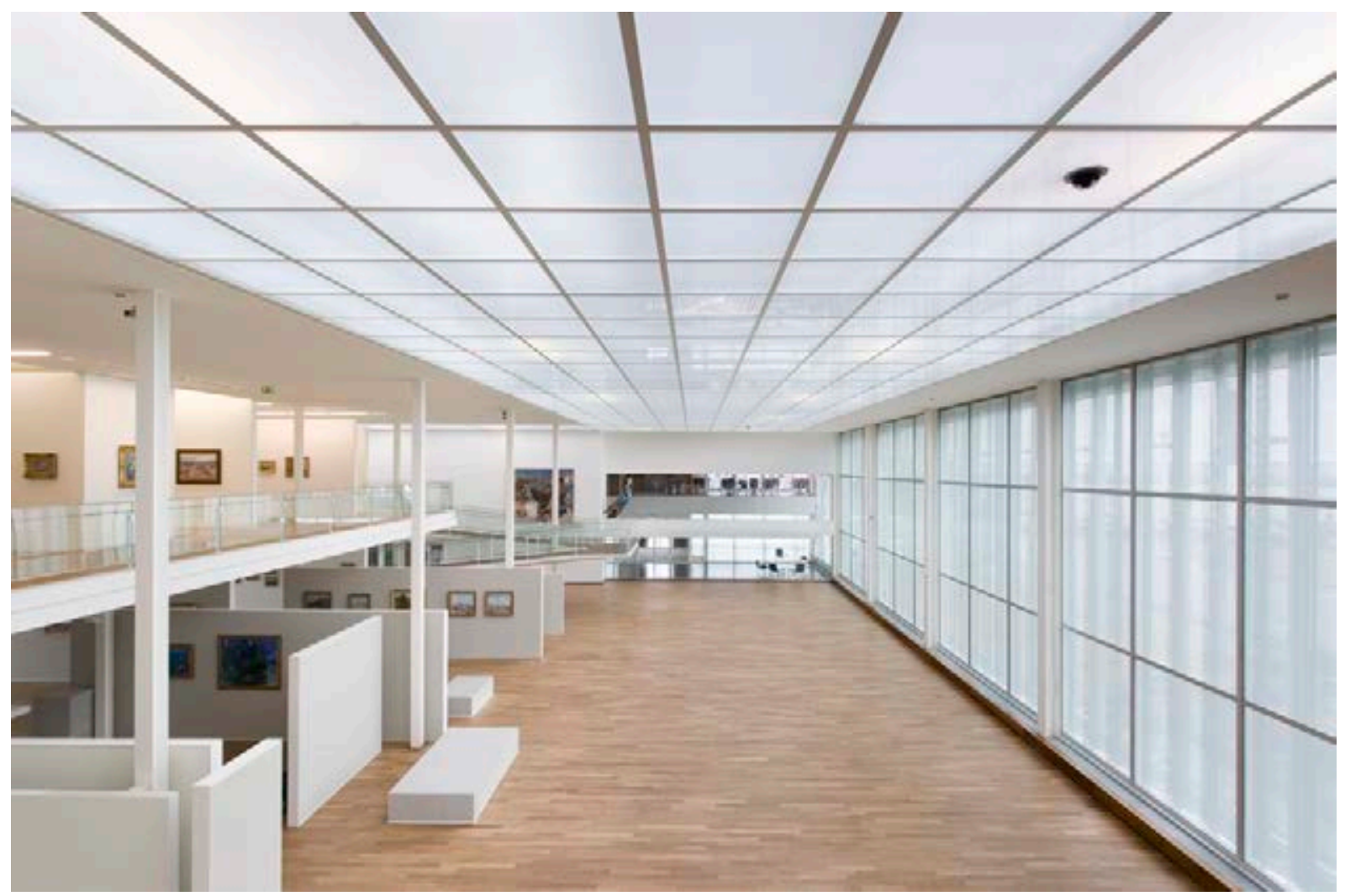

MuMa, ( ) MuMa Le Havre / Florian Kleinefenn

«las obras de arte dan vida a la gente que está enfrente de estas» ${ }^{4}$. Hay que recordar el valor que Malraux otorgaba a los museos, pues «el papel que juegan [...] en nuestra relación con las obras de arte es tan grande, que tenemos dificultad para pensar que no existe, que no existió jamás, allí donde la civilización de la Europa moderna es o fue desconocida, y que existe en nosotros después de dos siglos. El siglo XIX ha vivido de ellos, nosotros todavía vivimos y olvidamos que ha sido impuesto al espectador una relación completamente nueva con la obra de arte» (Malraux, 2016: 11-12).

Sin embargo, la citada hibridación comenzó a presentar problemas de convivencia, pues el espacio que necesitaba la casa cultural limitaba el trabajo del museo, esta inadaptación de la primera terminó ocasionando una ruptura

4 Palabras recogidas en un discurso pronunciado en 1966, publicado en Charles Louis Foulon (2016) y la consecuente disociación. El museo, conocido hoy como Musée d'Art Moderne André Malraux (MuMa), siguió su propio camino y consiguió consolidarse en el panorama museístico. De hecho, en agosto de 2019 ha celebrado el centenario de su fundación. Mientras, la Maison de la Culture fue languideciendo en el tiempo ${ }^{5}$, tras pasar por dos sedes diferentes, actualmente lo que queda de ella es la Scène Nationale du Havre, donde se lleva a cabo una amplia programación dedicada al teatro, principalmente.

El aporte que el MuMa ha realizado en la historia de la museología queda definido, principalmente por la relación que se es-

5 En el año 2009 se creó la Asociación Maison de la Culture de Le Havre que ha impulsado diferentes iniciativas para el estudio de esta institución, dando lugar a publicaciones y jornadas que han conseguido compilar una amplia información de las etapas precedentes. 
tablece entre arte y público, también por el lenguaje arquitectónico del edificio y por sus líneas de actuación, las cuales comenzaron a desarrollarse de forma innovadora durante los años cincuenta y sesenta, una etapa en la que se abren las colecciones a la sociedad francesa. Además, podemos decir que el MuMa - el cual se ha convertido en la segunda colección de pintura impresionista más importante por detrás del Musée d'Orsay - es el resultado de un proceso de transformación que ha ido al compás de los planteamientos surgidos en materia de políticas culturales, museografía y arte urbano, el cual se inicia en la puerta de acceso al museo y se prolonga por diferentes espacios de la ciudad.

\section{La recuperación urbana de Le Havre, el esce- nario para la revitalización cultural}

Aunque los orígenes de las Maisons de la Culture están vinculados a los inicios de la v República Francesa (1958), en realidad este modelo de institución procedía de los años treinta, cuando André Malraux estuvo en contacto con el Frente Popular y tenía previsto fomentar la accesibilidad a la cultura ${ }^{6}$. Sin embargo, conviene recordar que en el caso de Le Havre este proyecto estuvo además directamente ligado a la reconstrucción de la ciudad por los desperfectos ocasionados tras la destructiva Segunda Guerra Mundial ${ }^{7}$. Desde julio de 1959, tras ser nombrado ministro de cultura por el presidente Charles de Gaulle, Malraux volvió a recuperar la idea de casas culturales que pasaron de ser una utopía a convertirse en realidad.

\footnotetext{
6 No hay que olvidar que estas estuvieron, a su vez, directamente influidas por la denominada Maison du Peuple, ideada durante la Represión de la Commune de París en 1871, institución que estaba nuevamente ligada a un momento político. 7 Situación que también se produjo en otros lugares de la región francesa de Normandía, tal fue el caso de Rouen, y que supuso la pérdida de edificios como el antiguo Théâtre des Arts, que terminó siendo levantado en el antiguo emplazamiento convirtiéndose, desde entonces, en uno de los espacios culturales más representativos de la ciudad.
}

Asimismo, este modelo de institución respondía a un periodo de movimientos populares que cobraba fuerza en los años sesenta, tal y como se interpreta por el aumento del activismo artístico y cultural, que luchaba por la democratización y la accesibilidad a la cultura. El Ministère d'Affaires Culturelles pretendía mediante la red de Maisons de Culture prevista por todo el territorio francés, llevar a cabo una descentralización y una cooperación entre el Estado y las regiones. Al mismo tiempo, se iban tejiendo nuevas estrategias político-administrativas en estas casas de provincia, las llamadas «Association de la Masion de la Culture», a las que se fueron adhiriendo numerosos socios, en algunas localidades como en Grenoble llegaron a alcanzar los treinta mil miembros. No hay que olvidar el marco en el que se desarrollan estas instituciones, el cual coincide con los movimientos del Mayo del 68. De tal manera que, la noción de cultura en su diversidad más social dio lugar a la creación de la Maison des Jeunes, entre otras asociaciones populares, las cuales también tuvieron sus propios ecos en las reivindicaciones culturales.

El marco en el que emerge este movimiento de democratización fue en Le Havre, ciudad que quedó gravemente dañada por los bombardeos que sobre ella lanzaron las tropas aliadas durante el 5 y el 6 de septiembre de 1944, lo que supuso la completa destrucción de su centro histórico, incluyendo el Museo de Bellas Artes y el Teatro Municipal. Tras la Liberación, se puso en marcha un plan de recuperación urbanística a través de un equipo de arquitectos, cuya dirección fue confiada a Auguste Perret, que trabajó junto al Ministère de Reconstruction et de l'Urbanisme y la secretaría de Bellas Artes. El director de los museos de Francia, Georges Salle, también se involucró en esta tarea de recuperación, en apoyo al alcalde de la ciudad portuaria, Pierre Courant, que solicitaba la reconstrucción del museo lo antes posible, cuyo edificio históri- 
co había sido arrasado. En 1946 se daban los primeros pasos para levantar el núcleo poblacional, a través de amplios ejes principales y ordenación de los monumentos, estableciéndose un criterio homogéneo entre los miles de edificios previstos, los cuales tendrían tanto categoría residencial, como también de carácter religioso, civil, administrativo o comercial. No hay que olvidar que en medio de este proyecto hubo un gran interés por revitalizar el centro urbano y el área metropolitana a favor de las artes y la cultura, como años después se haría en París con el casco histórico y el Centre Pompidou. Esta intervención que ha sido calificada de «ejemplo excepcional del urbanismo y la arquitectura de posguerra» (Critère $I V)$, y ha contado con el reconocimiento de la UNESCO en 2005, quedando inscrito en la lista del Patrimonio Mundial de la Humanidad. Los aspectos más destacados que han permitido esta inclusión han sido el modelo de unidad en el método de recuperación, la integración entre pasado y presente, el respeto por las huellas históricas, la incorporación de nuevos avances en arquitectura moderna y técnicas constructivas, donde el hormigón se convertía en el material principal. No hay que olvidar que el MuMa también contribuyó a la inscripción de la cuidad en la UNESCO, al ser uno de los organizadores de la exposición $\mathrm{Pe}$ rret, la poétique du béton armé, muestra que supuso el despertar del reconocimiento urbanístico y paisajístico al integrarse el arte contemporáneo en el paisaje, privilegiándose una imagen renovada de este proceso de cambio y transformación.

\section{El MuMa: de un museo local a una institu- ción de referencia}

La creación del Musée d'Art Moderne se debe al pintor Reynold Arnould, que fue el visionario de esta institución (Reneau, 2011) creada para salvaguardar la colección del primer mu- seo de la ciudad ubicado en el antiguo «Logis du Roi», cuyo edificio fue destruido por los bombardeos, aunque sus obras fueron puestas a salvo, y estas constituyeron el punto de partida de la institución actual. Su impulsor la concibió tomando como referencia el modelo de museología americana que había conocido durante su estancia en Estados Unidos donde fue profesor en la Universidad de Texas, allí entró en contacto con críticos, visitó galerías y museos. En su ciudad natal, Le Havre, pondría en práctica la influencia que traía, quería entonces "crear un museo de arte moderno orientado hacia América» (Reneau, 2016: 83), mientras que a nivel internacional el modelo americano no sería seguido hasta los años sesenta (Lorente, 2018). No solo asumió esta importante tarea de dirección y recuperación, sino que además intervino en los museos de la ciudad portuaria que habían sido arrasados. Sin embargo, apostó por el antiguo $\mathrm{Mu}$ seo de Bellas Artes para que este se convirtiera en uno de los emblemas arquitectónicos de la ciudad. Esta decisión también influyó en la transformación de la colección que derivó hacia el periodo contemporáneo y quería que fuera «tanto exigente y moderna, como abierta y accesible a todos los públicos» ${ }^{8}$, un hogar para el arte, la educación y la cultura.

Además de ser Arnould el primer director, también fue conservador, y estuvo como máximo responsable desde 1952 hasta 1965; en aquel entonces era habitual nombrar para estos cargos a pintores locales. En 2019, con motivo de los actos celebrados por el centenario del museo, se rememora la etapa en la que estuvo al cargo de la colección. De tal manera que bajo el título Reynold Arnauld et le Musée du Havre (1952-1965) ${ }^{9}$, se recogen las principales actuaciones de la institución, como fue el inventario

8 http://www.muma-lehavre.fr/fr/expositions/reynold-arnould-et-le-musee-du-havre-1952-1965 [Consultado el 18 de septiembre de 2019].

9 La muestra tendrá lugar del 7 de diciembre de 2019 al 16 de febrero de 2020. 
de la colección. Pero también se impulsó una política de adquisición de obras de arte contemporáneo ${ }^{10}$ y se inició un programa de exposiciones temporales y actividades culturales. Asimismo, citar que los años claves de la institución se contemplan en la muestra Construire le musée imaginaire: Le Havre 1952/1961/1965 (2011), que también hace referencia a la etapa de Arnould. Tras dejar su cargo en el museo, pasó a dirigir las Galeries Nationales du Grand Palais, donde comisarió exposiciones nacionales e internacionales, siguiendo el modelo museográfico que había puesto en marcha en Le Havre. No hay que olvidar que el edificio respondía a las nuevas necesidades que Arnould concebía en materia de museos y que incluía desde salas de exposiciones, una cafetería, sala para la proyección de cine, celebración de debates, conciertos, es decir, espacios polivalentes, abiertos a la sociedad que convierten el museo en un organismo vivo. Años más tarde, el Centre Pompidou presentaría un edificio con un planteamiento similar de carácter multidisciplinar que fue muy influyente para otros museos.

Al igual que se han ido produciendo varias transformaciones en el museo de Le Havre, el nombre de la institución también ha cambiado paralelamente. De tal modo que, si en sus orígenes se llamaba Musée de Beaux-Arts, desde su refundación en 1952 hasta 1961, pasó a ser Musée du Havre. Sin embargo, al fusionarse con el proyecto de Malraux se rebautizó con el nombre Musée-Maison de la Culture du Havre. Al producirse la desvinculación entre ambas en 1967, pasaría a ser Musée de BeauxArts André Malraux y, finalmente, tras las últimas remodelaciones efectuadas en los años noventa, adquirirá el nombre de MuMa-Musée d'Art Moderne André Malraux.

10 La colección ha ido creciendo de forma continua en el tiempo, a través de donaciones, depósitos o adquisiciones. En relación con estas últimas señalar, por ejemplo, que en el año 2019 se han incorporado obras como Barque échouée sur la grève (1956) de Georges Braque; o Le Havre, le bassin (1906) de Albert Marquet.
Es evidente que la huella del primer ministro de cultura quedó plasmada en esta ciudad, en donde encontró el lugar apropiado para poner en marcha la descentralización y la democratización cultural, pues quería romper con el aislamiento y el elitismo que tradicionalmente tenía la cultura artística. En su lugar, quería hacer «accesibles las obras capitales de la humanidad y, en primer lugar, de Francia, al mayor número posible de franceses; asegurar la más amplia audiencia a nuestro patrimonio cultural, y favorecer la creación de las obras de arte y el espíritu que las enriquece» (Reneau, 2016: 34). No hay que olvidar que para muchos países europeos la cultura francesa suele ser vista como un asunto de Estado, especialmente en temas de gestión y financiación. De tal manera que, los «gobiernos han comenzado a ver la utilidad de tener, siguiendo el modelo francés, un ministerio de cultura independiente que recurra a la administración local y al sector privado, según convenga» (Georgina, 1999: 31).

Con respecto a la colección del museo, esta se caracteriza porque conserva obra tanto de maestros del pasado como de artistas del presente, cuyo fondo se amplía continuamente a través de varias vías de ingreso, principalmente donaciones, legados y adquisiciones, como así sucedió en otros museos especialmente tras la Segunda Guerra Mundial, momento en el que se produjo un cambio significativo en el panorama museístico. El origen del Musée du Havre, que se remonta a 1845 , era muy modesto y «se enriqueció considerablemente con compras muy juiciosas por el Ayuntamiento» (Barnaud, 1982: 184). Predomina la pintura europea desde el Renacimiento -incluyendo la escuela flamenca, la italiana y la holandesa- y el siglo XVII y XVIII, con obras de Fragonard, Robert, Delacroix, Millet y Doré, entre otros pintores. Aunque actualmente es conocida por albergar un gran número de paisajes impresionistas, neoimpresionistas, nabis y fauvistas realizados por artistas de renombre desplazados hasta los 


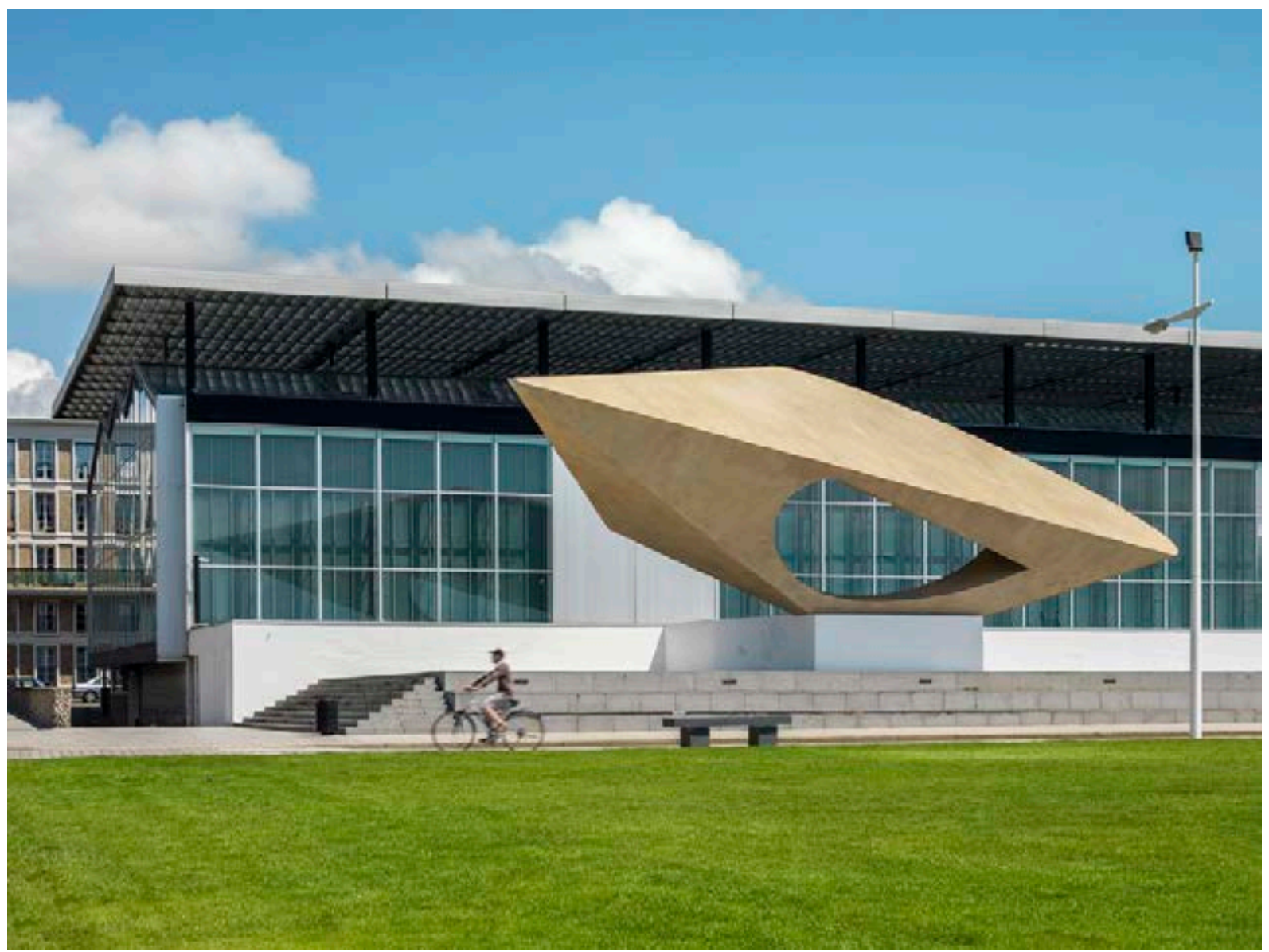

MuMa y la Signal, (c MuMa Le Havre / Florian Kleinefenn

alrededores de esta ciudad normanda y que hoy forman parte del discurso de la exposición permanente. Además citar a Dufy, Pissarro, Monet, Renoir, Sisley, Bonnard, Courbet, Dubuffet, entre otros, que convierten esta colección en un referente del siglo xIX y xx, principalmente tras la incorporación de fotografía contemporánea. Con respecto a los donantes, destacan numerosos nombres de coleccionistas ${ }^{11}$ de la localidad

11 Citemos la donación de Laurent Beaudouin, Sandra Barclay o Hélène Senn-Foulds. Esta última ha nutrido la institución en repetidas ocasiones, desde 2004 hasta 2009, con obra procedente de la colección de su padre, Olivier Senn. Por esta vía ingresó un importante legado de pintura impresionista, aunque también tenía una acuarela de Picasso de 1904, y de otros artistas como Pierre Lesieur, Roger Muhl, Charles Lacoste o Yvan Pougny, entre otros. La última donación se produjo en 2014 por Pierre-Maurice Mathey, el nieto de Olivier Senn, que entregó dieciocho obras al museo, completando el fondo procedente del coleccionista. que hicieron destacadas aportaciones, entre los primeros que ingresan se encuentra el legado de Charles-Auguste Marande en 1936, que contenía obra de los grandes nombres del impresionismo y del fauvismo (Monet, Renoir, Pissarro, Marquet, Van Dongen), y el legado de Madame Dufy en 1963. Estas obras fueron expuestas siguiendo el criterio del primer director del museo, un discurso cronológico cuya museografía se regía por la simplificación, mediante la presentación de las obras sin marco, colgadas directamente sobre un panel, favoreciendo un diálogo entre la pintura y el espectador para que fuera más directo, individual y sincero.

Las exposiciones temporales se pusieron tempranamente en marcha para acercar el arte a la sociedad, a través de muestras itine- 
rantes que cumplían la función de educación popular, produciéndose así ese encuentro directo que defendía André Malraux y que suscitaba numerosos interrogantes sobre cómo atraer el público al museo, cómo ir a su encuentro y presentar las obras fuera del museo, es decir, una serie de cuestiones que continúa planteándose actualmente la museología. Así como, ofrecer el acceso del público a los contenidos culturales y buscar las vías posibles, bien sean expositivas o bien en actividades educativas, para que se produzca la transferencia del conocimiento.

Entre las muestras que se han celebrado cabe destacar Les territoires du désir ou les métamorphoses d'un musée imaginaire (20112012), que forma parte del programa del cincuenta aniversario de esta institución, en la que se retoma el modelo utópico de Malraux que en esta ocasión recupera el MuMa para presentar nuevos diálogos entre pinturas antiguas de Renoir, Courbet o Boudin y fotografías contemporáneas de Albert Marquet o de Sabine Meier, dando un salto en el tiempo. Pero, a su vez, «el museo debe alcanzar en la actualidad algún tipo de conexión, de interrelación con el público» (Arrieta, 2014: 10) y como muestra de esto hay que mencionar a los artistas locales que han sido convocados para que trabajen en el paisaje urbano mediante intervenciones realizadas en el espacio público recuperado por Auguste Perret, las cuales se ejecutan in situ. De este modo, se convierte la calle en la prolongación del MuMa. Esta integración del arte en la arquitectura y el urbanismo ha contribuido a la creación de un patrimonio con identidad propia. Pues «el gesto más simple para dar identidad a un lugar, a una plaza, es colocar una escultura, generadora de agregaciones espaciales, referencia natural para los usuarios. Es el procedimiento primordial para transformar un lugar indiferenciado en un espacio» (Favole, 1995:
10). A su vez, estas esculturas han contribuido en la creación de nuevos diálogos.

Desde 2017, en Le Havre, el arte urbano ha adquirido un importante impulso. Ese año se produjo la conmemoración del quinto centenario de la ciudad, que se celebró con numerosas actividades culturales, como fue la exposición titulada Un été au Havre (Shenouda, 2017), que supuso un cambio global de la ciudad. El director artístico fue el francés Jean Blaise, que se encargó de la dirección de un proyecto compuesto por numerosas esculturas contemporáneas de amplias dimensiones y de carácter efímero, que tenía como fin crear lugares culturales. En este sentido, las obras se integraban en la arquitectura, plazas y monumentos, con el objetivo de dar un nuevo impulso a este núcleo portuario e industrial dotándole de un aspecto de modernidad. También para "poner en valor las calles, la orilla y sus comercios, devolviendo el gusto de desplazarse en este entorno» (Thomas, 2019). En 2019 se celebra en Le Havre la tercera edición, resultado del gran éxito que consigue cada año, donde el arte vuelve a integrarse en el patrimonio urbanístico de la ciudad, esta vez nueve obras se suman a la lista anterior. Uno de los más llamativos es el trabajo del brasileño Henrique Oliveira, este ha representado con el título Sisyphus Casemate la invasión de la naturaleza a través de una enorme raíz de árbol que ocupa un amplio espacio.

Entre las ocho obras que finalmente se ha optado por su conservación para que pasen a formar parte de la imagen de la ciudad, se encuentra la escultura La Catène, del artista Vicent Ganivet, compuesta por contenedores multicolores en forma de arco; y Tout comme UP\#3, de Lang/Baumann, se trata de una estructura de cemento ubicada en la playa y que representa una fusión imaginaria entre el océano y la ciudad. 
El emblema arquitectónico del Musée d'Art Moderne André Malraux

El MuMa se convirtió en el primer gran museo francés de la posguerra y en un icono de modernidad por el diseño arquitectónico, cuya estructura ligera y cubrimiento transparente dominan la estética de esta obra maestra que forma parte «de un linaje de edificios que van a marcar el fin del siglo $\mathrm{xx}$, donde la familia probablemente no ha terminado de crecer» (Beaudoin, 1999: 22). De hecho, es junto al Museo de Arte Contemporáneo de São Paulo, de Lina Bo Bardi y el Museo de Arte Moderno en Río de Janeiro, de Affonso Reidy, «uno de los museos mayores de mitad del siglo XX» (Beaudoin, 1999: 22). Más allá de su dimensión, también forma parte de la historia de la ciudad, pues su origen se integra dentro del capítulo de reconstrucción urbanística de la posguerra. El reconocimiento de los méritos arquitectónicos alcanzados no fue inmediato, pese a conseguir un premio y realizarse numerosas publicaciones.

El museo había perdido por completo su antiguo emplazamiento tras ser bombardeado; para el nuevo edificio se seleccionó un terreno ubicado frente al mar. El equipo encargado del proyecto se componía de los arquitectos ${ }^{12}$ Weill, Lagneau, Dimitrijevic y Audigier. El edificio destaca por sus grandes paneles acristalados, estructuras en acero y aluminio que acoge una amplia luz solar. Más que soluciones innovadoras se buscaba una coherencia e integración. El concepto de modernidad del edificio estuvo, a su vez, impulsado por los diferentes espacios polivalentes que se incorporaban, como fueron la librería, la cafetería, la biblioteca, la sala de conferencias o el área de administración. Su primer director, Reynold Arnould, quien mantenía una estrecha

12 También contaron con el apoyo de un equipo de ingenieros compuesto por Laffaille, Sarger, Prouvé y Salomon, aportando cada uno una especialidad distinta, bien en hormigón, el empleo del aluminio o bien la iluminación natural y artificial. relación con los arquitectos, tuvo una participación directa aportando ideas como fue la apertura de la colección a través de espacios abiertos y la creación de una escenografía innovadora para que atrajera al público más reticente.

Este edificio pionero que «ha marcado de una forma destacada la evolución de la arquitectura» (Beaudoin, 1999: 22), rompe con el plan de recuperación de Auguste Perret y con el modelo tradicional de los museos de la época, ya que en todo momento va a predominar la modernidad de los espacios, a través de la flexibilidad, la cual «será explotada hasta llegar a ser una dimensión mítica propia de la arquitectura de los años sesenta» (Beaudoin, 1999: 22), y la transparencia, «el axioma fundador del Musée du Havre, aquel también de su rango mítico» (Beaudoin, 1999: 22). Por tanto, su fluidez, la abertura hacia al mar y la flexibilidad de los espacios polivalentes se oponen al racionalismo y al empleo del hormigón que se convirtió en el material por excelencia en la reconstrucción urbanística en la ciudad portuaria, el cual impedía conseguir las características anteriores. El efecto que se consigue en el interior es de una gran iluminación tanto cenital como lateral y permite establecer una comunicación constante entre la colección expuesta y el exterior, gracias al acristalamiento de sus cerramientos. Los principales logros de este edificio, que llegó a ser reconocido como «uno de los más modernos de Europa» (Barnaud, 1982: 184), fueron posteriormente recogidos en el proyecto del Centre d'Art et Culture Pompidou, diseñado por Piano y Rogers e inaugurado en 1977.

El MuMa tuvo una remodelación entre 1995 y 1999, una intervención más interna que externa cuyo fin principal era reorganizar espacios y crear otros nuevos, por ejemplo, para talleres pedagógicos. También se intervino en las salas expositivas y se recurrió a la 
tecnología contemporánea, incorporándose cristales serigrafiados para que filtraran la luz y protegieran la obra. Además, se hicieron mejoras en la fluidez de comunicación y la circulación que se articula en dos plantas, a las que se accede por una rampa, desde la cual se quiere reforzar el diálogo entre la colección y el entorno, y los vínculos visuales con el paisaje marino. Se busca principalmente una mayor integración de la pintura impresionista y el escenario de buena parte de estas obras, cuyos artistas eligieron este enclave para llevarlas a $\mathrm{cabo}^{13}$, por lo que también se diseñaron rutas para que el visitante continuara su visita más allá del museo ${ }^{14}$.

El escultor Henri-Georges Adam fue el encargado de ubicar una de sus obras en la explanada de acceso, que destaca por sus grandes dimensiones -alcanzando los 22 metros de alto y 220 toneladas- y fue realizado en hormigón armado, pues su autor buscó mantener una sintonía con el material de Perret que además representaba los tiempos modernos. Con el título The Signal (1961), Adam optó por un diseño que aparentemente tiene forma de flecha o de vela, según se mire, porque su forma va cambiando en función de la perspectiva que se adopte, consiguiendo una imagen cambiante. Su creación se hizo a petición del Estado en 1956, para ocupar la parte de la entrada al museo, una zona estratégica ya que representa la antesala de la institución (Lorente, 2018) pues se integra como parte de la misma y, a su vez, se convierte en un puente entre el museo, el mar y el puerto.

13 Recordemos la conocida École de Rouen que integraba numerosos artistas, algunos locales, que hicieron desde finales del siglo xIX una importante producción pictórica, principalmente neoimpresionista y postimpresionista, en torno a los paisajes de esta ciudad. Actualmente, el Musée de Beaux-Arts de Rouen dedica una sala expositiva a esta generación. 14 Actualmente siguen poniéndose en marcha estas ideas, así por ejemplo, citar los «Paseos frente el mar con Raoul Dufy», una actividad que se realiza fuera de los muros del museo y que busca los vínculos entre el paisaje y la obra del pintor, con motivo de la exposición Raoul Dufy au Havre (2019).
Otras obras escultóricas que se exponen en los alrededores del museo son Outres (1999) de Vincent Barré, compuesta por tres piezas en hierro; una de ellas fue donada por el artista, las restantes se adquirieron para remplazar el depósito de Le Navigateur que Ossip Zadkine retiró hace tiempo y cuya instalación se hizo en 1961. La ubicación era la misma que la anterior, sobre los estanques que rodean el museo, estableciendo nuevamente esa relación entre el público y el exterior, con el interior y la colección.

Pero las huellas de la arquitectura moderna no se detienen en el edificio del MuMa, que desde 1967 había dejado de ser la sede de la Maison de la Culture. Esta pasó a ubicarse en el teatro del ayuntamiento de la ciudad, sin embargo, tres años después se comenzó a plantear la creación de una sede definitiva, gestión que no concluiría hasta 1982. Se necesitaba un edificio que acogiera un espacio multifuncional para desdoblar sus funciones, junto a salas de espectáculos, de cine, de exposiciones y para el comercio. El nuevo edificio corrió a cargo del arquitecto brasileño exiliado en París, Oscar Niemeyer, quien comenzó el proyecto en 1972 y lo terminó junto a Jean-Maur Lyonnet; ambos estudiaron la adaptación del edificio a su funcionalidad. Entre 1978 y 1982 se levantó lo que se consideró el último encargo realizado en el marco de la reconstrucción de la ciudad, esta vez adoptaba la forma de chimeneas y por sus características comulgaba con el plan urbanístico de Perret. De tal manera que las formas ortogonales propuestas por este último dialogan con las líneas curvas del anterior, al mismo tiempo que juega con el contraste entre las escalas y los niveles. Se trata de dos edificios avolcanados que están separados por una plaza de la que emergen, pues como dice el propio arquitecto, «quise hacer una estructura para el hombre que camina y que ve desde diferentes puntos de vista» (Saint-Pierre, 2017: 150). Uno de estos volúmenes está dedicado a 


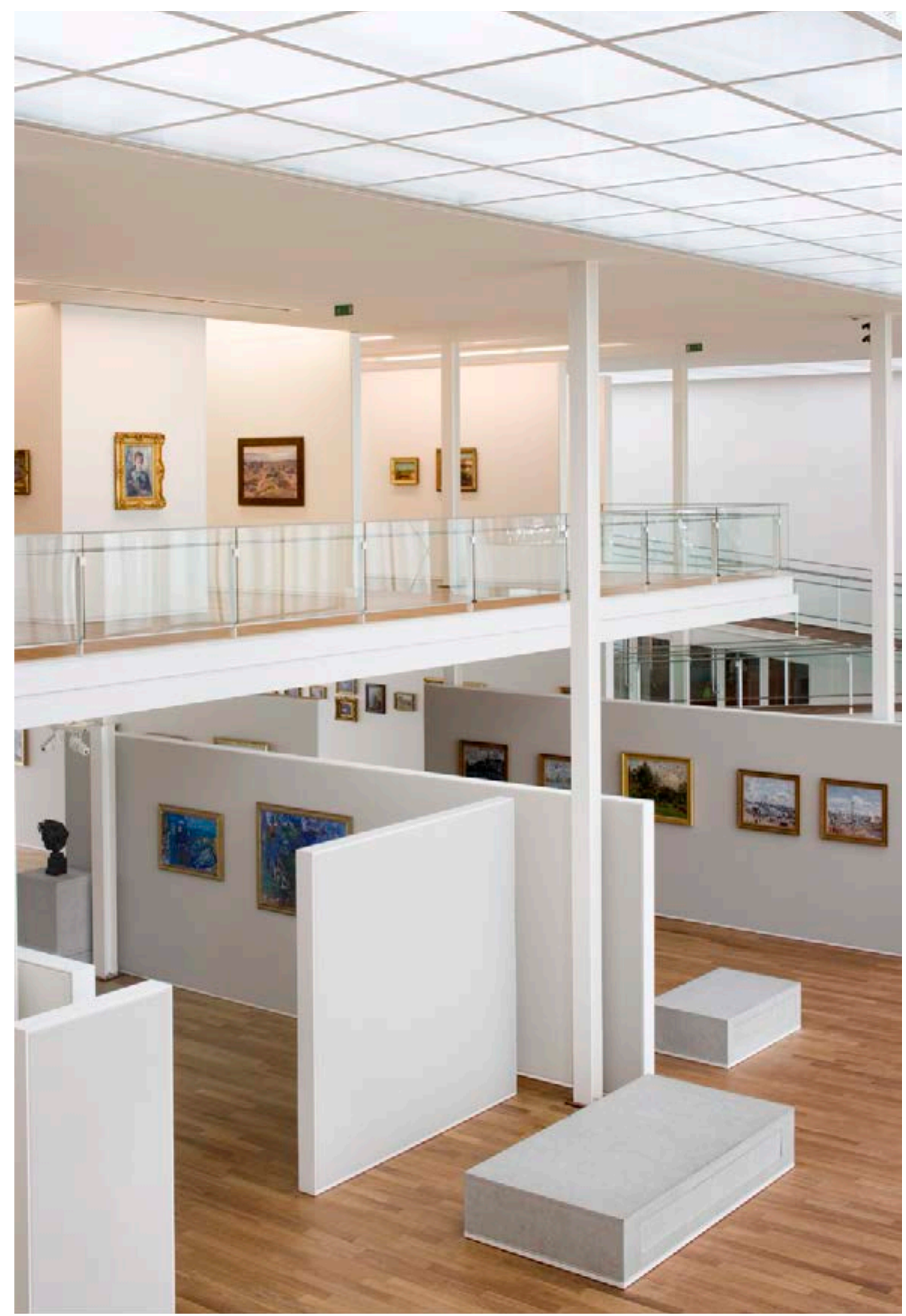

Vista general del interior del MuMa, ( ) MuMa Le Havre / Florian Kleinefenn 
la Biblioteca Oscar Niemeyer y el otro, al teatro y al cine y pertenece a la Scène Nationale du Havre, aunque es conocido con el nombre de «Le Volcan».

Este último proyecto es el que pasó a convertirse en la nueva sede de la Maison de la Culture, aunque se alejaba de la idea original, porque dejó de tener una colección para contar solo con un hall de exposiciones, por tanto, quedaba reducida la parte artística, al igual que el concepto de "Catedral del siglo xx» definida por Malraux, es decir, la propuesta de integración de todas las artes a través de un proyecto multifuncional que, en esta ciudad, quedaba dividido en varios edificios.

\section{Conclusión}

Las huellas de la modernidad en Le Havre han pasado desapercibidas en los estudios de la museología, pese al avance de las aportaciones que realizó desde el ámbito de la arquitectura y la democratización cultural. Si el ministro André Malraux eligió el museo municipal como sede para la primera Maison de la Culture es porque vio en esta recién inaugurada institución el emblema de la modernidad. Las regiones francesas, por su carácter localista, suelen quedar eclipsadas por el deslumbramiento de París. Sin embargo, no hay que pasar por alto estas primeras iniciativas que surgen en los lugares más insospechados y que abanderan proyectos innovadores, los cuales son los puntos de inflexión para iniciativas posteriores. Después de todo, al tratarse de una ciudad portuaria había una puerta abierta al influjo de ideas procedentes del continente americano, tal y como demostró Reynold Arnould, que consiguió, museísticamente hablando, crear un puente entre Francia y América. De la obra arquitectónica de este museo embebieron otros proyectos, como el Centre Pompidou, al igual que la pluralidad de espacios y su carácter polivalente, cuyos precedentes vol- vían a encontrarse en el museo de Le Havre. Asimismo, no hay que olvidar que al tratarse de un edificio que se abre hacia el mar y el entorno urbano, la integración entre arte, paisaje y sociedad se mantiene en la actualidad, tal y como se muestra en el auge que está adquiriendo el arte urbano en esta ciudad.

\section{Bibliografía}

Arrieta Urtizberea, Iñaki (2014) «Públicos y museos: entre la democracia cultural y la mercantilización del patrimonio», Arrieta Urtizberea, Iñaki (Ed.), La sociedad ante los museos: públicos, usuarios y comunidades locales, Bilbao: Universidad del País Vasco: 9-28.

BARnaud, Germaine (1982) Répertoire des musées et collections publiques de France, Paris: Éditions de la Réunion des musées nationaux.

Beaudoin, Laurent; COHEN, Françoise (1999) «Le Havre: la rénovation du Musée André Malraux», $L a$ Revue du Louvre et des musées de France, 2: 22-25.

Cabanne, Pierre (1990) Guide des musées de France, Paris: Bordas.

Critère IV. Le Havre, la ville reconstruite par Auguste Perret https://whc.unesco.org/fr/list/1181 [Consultado el 11 de septiembre de 2019].

De VARINe, Huges (2014) «Quelle place et quels rôles pour l'habitant dans son musée?», Arrieta Urtizberea, Iñaki (Ed.), La sociedad ante los museos: públicos, usuarios y comunidades locales, Bilbao: Universidad del País Vasco: 29-51.

Favole, Paolo (1995) La plaza en la arquitectura contemporánea, Barcelona: Gili.

Foulon, Charles Louis (2016) «Un grand rêve d'André Malraux, ministre de l'irrationnel. Les Maisons de la Culture, des cathédrales pour le XXe siècle», Culture et démocratie. Une histoire de la Maison de la Culture du Havre, Mont-Saint-Aignan: Presses Universitaires de Rouen et du Havre: 21-32.

Girard, Augustin; GENTIL, Geneviève (1996) André Malraux. Ministre. Les affaires culturelles au temps d'André Malraux 1959-1969, Paris: La Documentation Française.

«Impression, Le Havre», L’Actualité des musées et du patrimoine, $\mathrm{n}^{\circ} 9$ (2011-2012): 11.

Lorente, Jesús Pedro; QUESADA, Blanca (2009) Arte en el espacio público: barrios artísticos y revitalización urbana, Zaragoza: Prensas Universitarias Zaragoza.

- (2008) Los museos de arte contemporáneo: noción y desarrollo histórico, Gijón: Trea. 


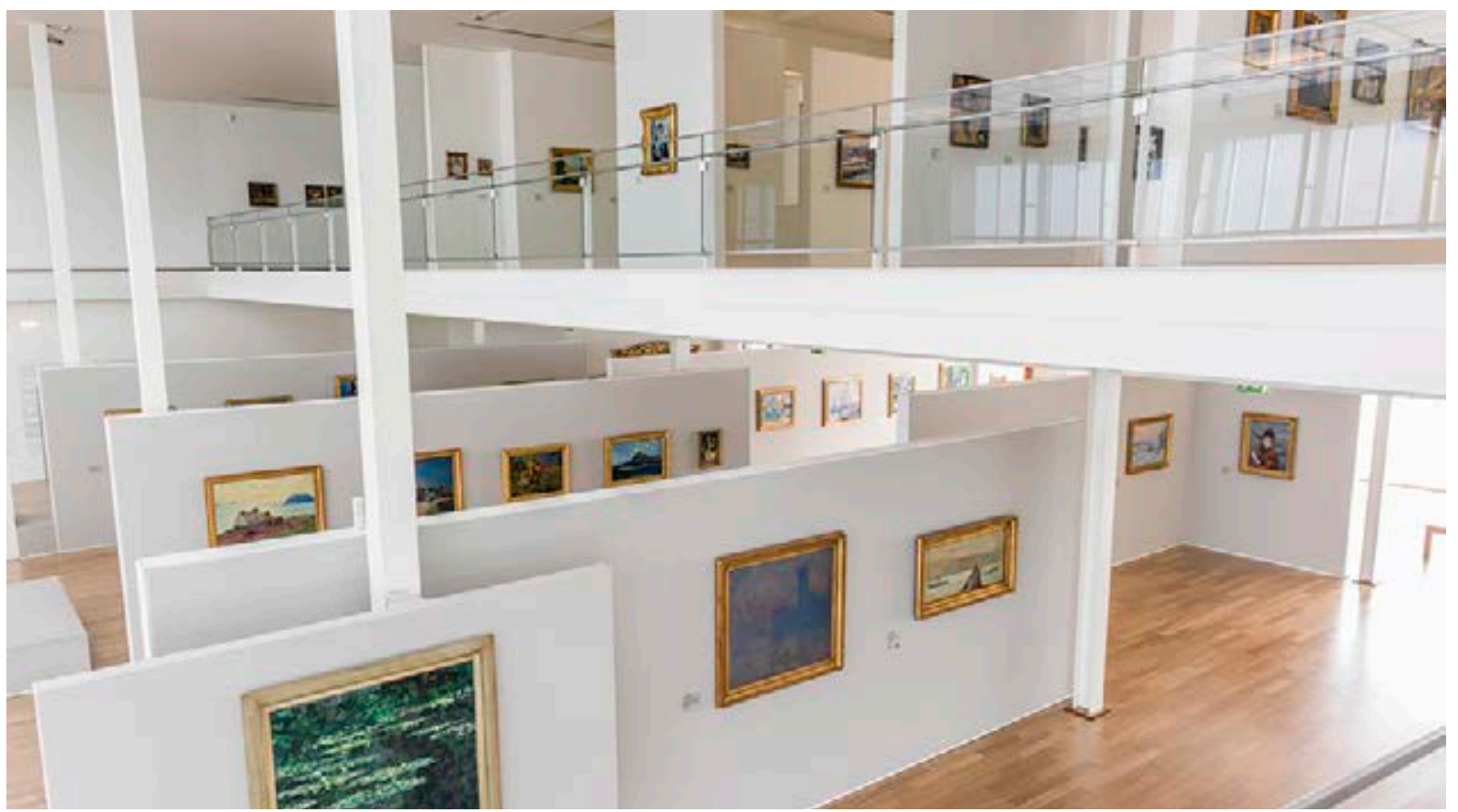

Vista general del interior del MuMa, ( MuMa Le Havre / Florian Kleinefenn

- (2018) Arte público y museos en distritos culturales, Gijón: Trea.

Malraux, André (2016) Le Musée Imaginaire, Paris: Gallimard.

Morère, Elisa (2019) «Entre terre et mer, le Havre célèbre un art XXL!» IDEAT. Doi: https://ideat. thegoodhub.com/2019/06/26/entre-terre-et-merle-havre-celebre-un-art-xxl/ [Consultado el 16 de septiembre de 2019].

Novarina, Gilles; Ruault, Jean-François (2016) «Le centre reconstruit du Havre», Les sites exceptionnels: quelle contribution au développement local?, Labex AE\&CC. Doi: https://halshs.archives-ouvertes.fr/ halshs-01614729/document [Consultado el 16 de septiembre de 2019].

Oliver, Georgina (1999) «El mecenazgo empresarial: un cambio racial en los museos franceses», Museum International, 202: 24-28.

ReAL López, Inmaculada (2019) «Los primeros espacios para la democracia sociocultural: la Maison de la Culture francesa», Revista de Museología. Publicación científica al servicio de la comunidad museológica, 74: 39-48.

Reneau, Serge (2002) Politiques et pratiques culturelles au Havre 1944-1983. Thèse d'histoire culturelle, Paris: IEP.

- (2011) «Reynold Arnould et les Musées du Havre, le temps des métamorphoses», Construire le musée imaginaire 1952-1965, Paris: Somogy.
- (2016) «La Maison de la Culture du Havre, l'État et la ville: 1961-1991», Culture et démocratie. Une histoire de la Maison de la Culture du Havre. MontSaint-Aignan: Presses Universitaires de Rouen et du Havre: 33-50.

- (2016) «L'inventeur du Musée d'Art Moderne, Reynold Arnould, premier directeur de la Maison de la Culture de 1960 à 1963», Culture et démocratie. Une histoire de la Maison de la Culture du Havre, Mont-Saint-Aignan: Presses Universitaires de Rouen et du Havre: 83-86.

Royer, Isabelle; BARot, Sylvie (2016) Culture et Démocratie. Une histoire de la Maison de la Culture $d u$ Havre, Mont-Saint-Aignan: Presses Universitaires de Rouen et du Havre.

Saint-Pierre, Raphaëlle (2017) «Oscar Niemeyer au Havre», Klein, Richard (Ed.) Les Maisons de la Culture en France. Paris: Éditions du Patrimoine, Centre de Monuments Nationaux: 147-166.

SHENoudA, Diane (2017) «Le Havre fête ses 500 ans en sculptures et en couleurs», Europe 1, le 27 mai. Doi: https://www.europe1.fr/culture/le-havre-feteses-500-ans-en-sculptures-et-en-couleurs-3343067 [Consultado el 14 de septiembre de 2019].

Recibido el 24 del 9 de 2019

Aceptado el 18 del 11 de 2019 BIBLID [2530-1330 (2019): 84-97] 